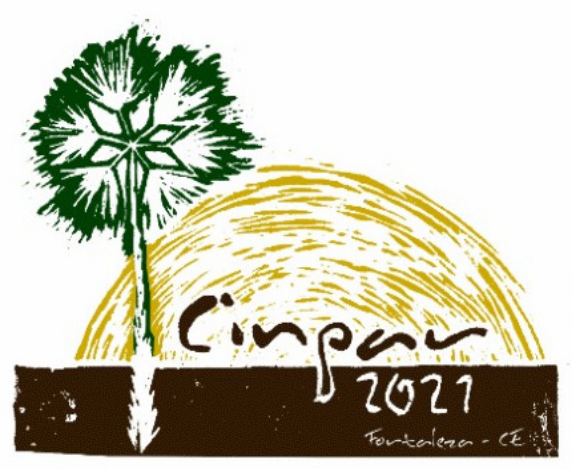

XVII Congresso Internacional sobre Patologia e Reabilitação das Construções

XVII Congreso Internacional sobre Patología y Rehabilitación de las Construcciones

XVII International Conference on Pathology and Constructions Rehabilitation

FORTALEZA (Brasil), 3 a 5 de junho de 2021

https://doi.org/10.4322/CINPAR.2021.144

\title{
Velocidade de Propagação de Onda Ultrassônica em Concretos com Fibras
}

\section{Ultrasonic Wave Transmission Velocity in Fiber Reinforced Concrete}

\author{
Wellington de Macedo $^{1}$, Luiz Carneiro ${ }^{2}$, Mayra Perlingeiro ${ }^{3}$ \\ ${ }^{1}$ Universidade Federal Fluminense, Niterói/RJ, Brasil, wellemencivil@hotmail.com \\ ${ }^{2}$ Universidade Federal Fluminense, Niterói/RJ, Brasil, luizcarneiro@id.uff.br \\ ${ }^{3}$ Universidade Federal Fluminense, Niterói/RJ, Brasil, mayraperlingeiro@id.uff.br
}

\begin{abstract}
Resumo: $O$ ensaio para determinação da velocidade de propagação de onda ultrassônica é um dos métodos não destrutivos mais utilizados para a avaliação da homogeneidade, a detecção de imperfeições e o monitoramento de variações ao longo do tempo em concretos. Este trabalho apresenta resultados da velocidade de propagação de onda ultrassônica obtidos a partir de concretos com fibras. Os espécimes de concreto possuíam resistência convencional ou alta resistência e continham diferentes tipos de fibras dispersas e descontínuas (aço, vidro, polipropileno, poliolefina, nylon e PET). Verificou-se que, dependendo do tipo de fibras, a velocidade de propagação de onda ultrassônica aumenta com o incremento do teor volumétrico de fibras e que a relação entre a velocidade de propagação de onda ultrassônica e a resistência à compressão do concreto com fibras parece existir de forma clara.
\end{abstract}

Palavras-chave: Velocidade de propagação de onda ultrassônica; Resistência à Compressão; Concreto; Fibras.

\section{Introdução}

O ensaio para determinação da velocidade de propagação de onda ultrassônica, aqui denominado ensaio de ultrassom, é um método não destrutivo, pois utiliza ondas mecânicas que não causam danos ao concreto, de modo que um corpo de prova de concreto pode ser testado repetidamente no mesmo local durante um período de tempo.

Os resultados desse ensaio são influenciados por diferentes fatores, dentre os quais, segundo a norma ABNT NBR 8802 (2019), destacam-se a distância entre as superfícies de contato dos transdutores do equipamento ultrassônico, a presença de armadura no concreto, a densidade, composição, condição de concretagem, tipo de adensamento e idade do concreto, o tipo dos agregados e do cimento, e a direção de ensaio.

Além desses fatores, Malhotra e Carinho (2004) acrescentam o modo de contato dos transdutores do equipamento ultrassônico no concreto, a temperatura, umidade e condição de cura do concreto, o tamanho e a forma do corpo de prova de concreto e o nível de tensão a que está submetido o concreto.

As falhas internas, homogeneidade, profundidade de fissuras e alterações no concreto, tais como deterioração devido à exposição em ambiente químico agressivo e danos acarretados por ciclos de congelamento e descongelamento, podem ser detectadas por meio do ensaio de ultrassom. Além disto, este ensaio é utilizado para se avaliar a resistência e a qualidade do concreto.

É de conhecimento geral que o concreto com fibras, dependendo do tipo e teor volumétrico das fibras, pode apresentar ou não resistência superior à do mesmo concreto sem fibras. Uma das formas para corroborar este resultado é submeter o concreto com fibras ao ensaio de ultrassom. 
Alguns estudos encontrados na literatura relataram que, dependendo do tipo de fibras, a velocidade de propagação de onda ultrassônica aumenta com o incremento do teor volumétrico de fibras. Outros estudos verificaram que existe uma relação entre a velocidade de propagação de onda ultrassônica e a resistência à compressão do concreto com fibras.

Neste trabalho, apresentam-se resultados encontrados na literatura sobre a velocidade de propagação de onda ultrassônica de diversos concretos com diferentes tipos de fibras dispersas e descontínuas (aço, vidro, polipropileno, poliolefina, nylon e PET) junto com a análise destes.

\section{Ensaio de ultrassom}

Neste ensaio utiliza-se um equipamento ultrassônico, que é dotado de circuito gerador-receptor, transdutoremissor e transdutor-receptor, circuito medidor de tempo, cabos coaxiais e barra de referência para aferição do equipamento. Na Figura 1, pode-se visualizar um equipamento suiço modelo TICO Ultrasonic Testing Instrument da marca Proceq. Possui dois transdutores de $54 \mathrm{kHz}$ e frequência de propagação da onda entre $24 \mathrm{kHz}$ e $500 \mathrm{kHz}$.

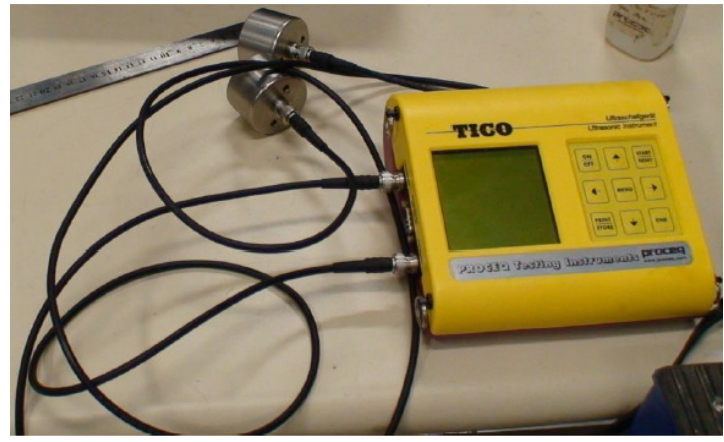

Figura 1 - Equipamento de ultrassom

Em laboratórios de pesquisa, em geral, cilindros de concreto servem como corpos de prova para o ensaio de ultrassom. O corpo de prova cilíndrico de concreto é deitado em uma superfície horizontal, após a superfície dos seus topos inferior e superior ser plana, lisa e limpa, e tem seu comprimento medido, como mostra a Figura 2a.

Uma fina camada de acoplante (vaselina) é aplicada nas faces dos transdutores e nas superfícies dos topos inferior e superior do cilindro de concreto, como pode ser visto na Figura $2 \mathrm{~b}$.

Os transdutores do equipamento ultrassônico são posicionados sobre as superfícies do corpo de prova cilíndrico de concreto, de modo que seja feita a leitura do tempo de deslocamento das ondas ultrassônicas entre os topos a fim de se obter a sua velocidade de propagação, de acordo com o que se vê na Figura 2c.

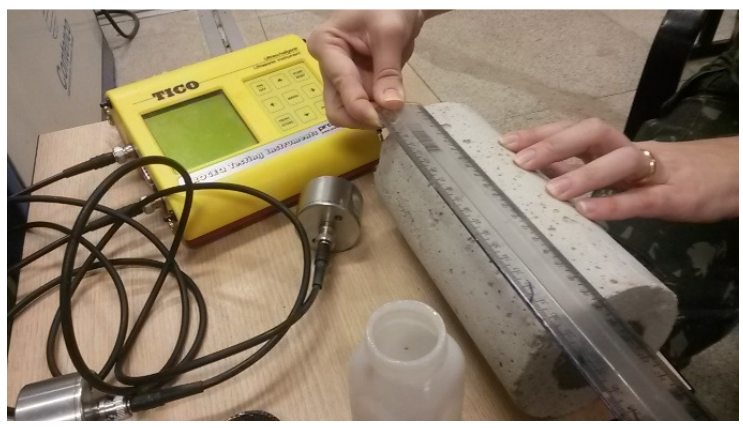

(a) Leitura do tamanho do cilindro de concreto

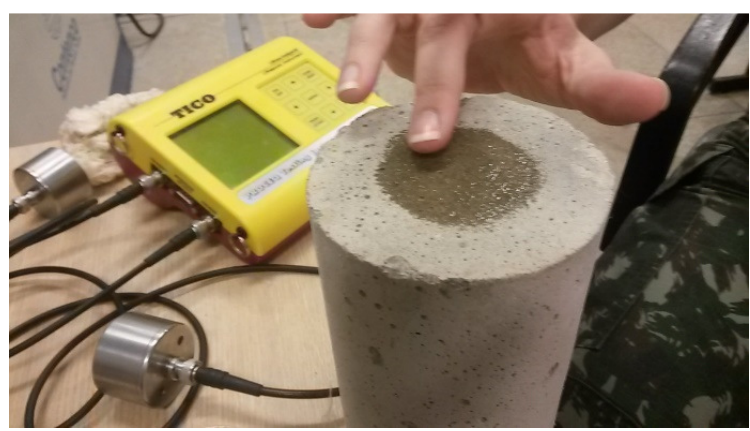

(b) Aplicação de vaselina no cilindro de concreto

Figura 2 - Etapas do ensaio de ultrassom em concreto (Saraiva, 2017) (continua) 


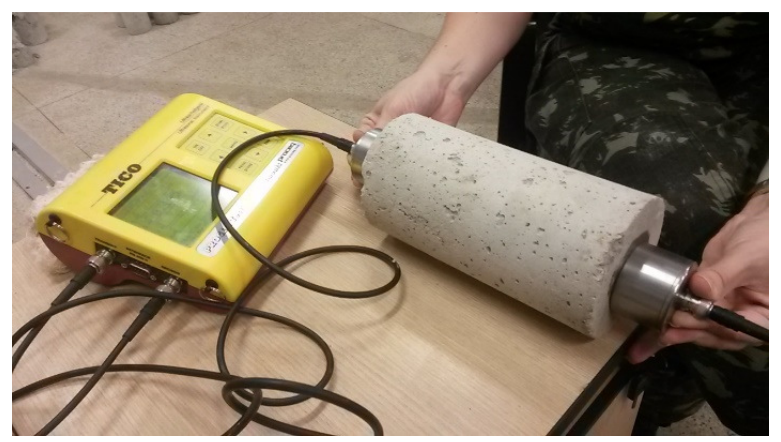

(c) Leitura do tempo de deslocamento das ondas ultrassônicas no cilindro de concreto

Figura 2 - Etapas do ensaio de ultrassom em concreto (Saraiva, 2017) (continuação)

Como os transdutores do equipamento ultrassônico são posicionados nos topos opostos do cilindro de concreto (v. Figura 2), a transmissão da onda ultrassônica é direta, de forma que a energia do pulso é máxima e é totalmente transmitida e recebida pelos transdutores.

Segundo a norma ABNT NBR 8802 (2019), além da transmissão direta exibida na Figura 2, existem a transmissão indireta com os transdutores na mesma face e a transmissão semidireta com os transdutores nas faces adjacentes, como se vê nas Figuras 3a e $3 b$.

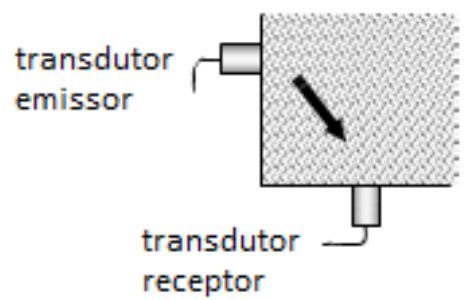

(a) Transmissão semidireta

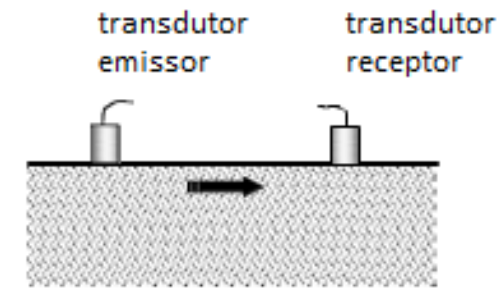

(b) Transmissão indireta

Figura 3 - Tipos de transmissão da onda ultrassônica em concreto

\section{Velocidade de propagação de onda ultrassônica}

A Equação 1 expressa a velocidade de propagação de onda ultrassônica, cujo valor é obtido por meio de um equipamento ultrassônico.

$$
V=L / t
$$

onde $V$ é a velocidade de propagação de onda ultrassônica, expressa em $\mathrm{m} / \mathrm{s}, L$ é a distância entre os pontos de acoplamento dos centros das faces dos transdutores, expressa em $\mathrm{m}$, e $t$ é o tempo decorrido desde a emissão da onda ultrassônica até a sua recepção, expresso em s.

Vários são os fatores influentes no valor da velocidade de propagação de onda ultrassônica, dependentes principalmente das propriedades e características do concreto.

Segundo Malhotra e Carinho (2004), caso a pressão de contato entre os transdutores do equipamento ultrassônico e o concreto seja realizada de maneira inadequada, a leitura de velocidade de propagação de onda ultrassônica pode ser incorreta.

Para uma mesma composição de concreto, o concreto com agregado do tipo cascalho apresentou velocidade de propagação de onda ultrassônica mais baixa, enquanto o concreto com agregado do tipo calcário, maior velocidade de propagação de onda ultrassônica. A velocidade de propagação de onda ultrassônica do concreto com agregado do tipo granito sitou-se entre as velocidades de propagação de onda ultrassônica destes dois outros concretos.

Para um concretos com valor de resistência à compressão similar, aqueles que continham maior teor de agregado apresentaram uma maior velocidade de propagação de onda ultrassônica. 
O tipo de cimento não influenciou significativamente a velocidade de propagação de onda ultrassônica, mas seu grau de hidratação, sim. Incrementos no grau de hidratação do cimento levaram ao aumento da velocidade de propagação de onda ultrassônica.

Com o acréscimo da relação água-aglomerante em concretos, a velocidade de propagação de onda ultrassônica diminuiu, desde que os outros componentes dos concretos fossem os mesmos.

A incorporação de ar em concretos pareceu não influir na relação entre a velocidade de propagação de onda ultrassônica e a resistência do concreto à compressão.

O efeito da idade do concreto na velocidade de propagação de onda ultrassônica foi semelhante ao efeito no desenvolvimento da resistência do concreto. A velocidade de propagação de onda ultrassônica aumentou rapidamente nas primeiras idades de cura do concreto e se estabilizou em um valor limite antes do concreto atingir sua resistência.

Variações de temperatura entre $5{ }^{\circ} \mathrm{C}$ e $30^{\circ} \mathrm{C}$ não tiveram efeito significante na velocidade de propagação de onda ultrassônica. Para temperaturas até $60^{\circ} \mathrm{C}$, recomendou-se que se aumente a velocidade de propagação de onda ultrassônica em até $5 \%$, enquanto para temperaturas até $-4{ }^{\circ} \mathrm{C}$, se diminua a velocidade de propagação de onda ultrassônica em até 1,5\%.

A velocidade de propagação de onda ultrassônica de concretos saturados foi $4 \%$ a $5 \%$ maior que a de concretos secos ao ar.

Comprimentos de caminho percorrido pela onda ultrassônica em concreto menores tenderam à velocidade de propagação de onda ultrassônica mais variável e um pouco mais alta, devido à natureza não homogênea do concreto.

Na maioria dos casos, a velocidade de propagação de onda ultrassônica não depende do tamanho e da forma de um corpo de prova de concreto. Para concreto com velocidade de propagação de onda ultrassônica de cerca de $3700 \mathrm{~m} / \mathrm{s}$ e para frequência de transdutor de $54 \mathrm{kHz}$, o comprimento da onda ultrassônica é de cerca de $68 \mathrm{~mm}$. Portanto, um corpo de prova deste concreto, quando ensaiado com transdutor de frequência de $54 \mathrm{kHz}$, deve ter dimensão lateral mínima de $70 \mathrm{~mm}$.

A dimensão máxima do agregado graúdo também deve ser menor que o comprimento de onda ultrassônica, caso contrário, a energia da onda ultrassônica é atenuada a ponto de nenhum sinal claro ser detectado no transdutor receptor.

A velocidade de propagação de onda ultrassônica geralmente não é afetada pelo nível de tensão no concreto. No entanto, quando o concreto é submetido a um nível muito alto de tensão (acima de $65 \%$ da resistência), formam-se microfissuras no interior do concreto, o que reduz consideravelmente a velocidade de propagação de onda ultrassônica (Malhotra e Carinho, 2004).

\section{Estudos sobre concretos com fibras}

O Quadro 1 mostra algumas características (forma e dimensões dos corpos de prova, resistência média do concreto à compressão $f_{c}$, tipo, comprimento $l_{f}$ e diâmetro equivalente $d_{f}$ das fibras) dos concretos com fibras coletados na literatura, que foram utilizadas na análise feita neste trabalho.

Os corpos de prova de concreto com fibras eram, em sua maioria, cilindros de $100 \mathrm{~mm} \times 200 \mathrm{~mm}$ ou de $150 \mathrm{~mm} \times 300 \mathrm{~mm}$ (diâmetro x altura) de dimensões. Nos estudos de Nik e Omran (2013), Rahmani et al. (2013), Al-Ridha et al. (2017), Tsioulou et al. (2017), Hassiba et al. (2018) e Shiade e Tavakoli (2018), foram ensaiados cubos de $100 \mathrm{~mm}$ de aresta. Placas quadradas de $300 \mathrm{~mm} \times 100 \mathrm{~mm}$ de dimensões também foram usadas nos ensaios de Gaspar (2016).

Em todos esses corpos de prova, a velocidade de propagação de onda ultrassônica foi obtida por meio da transmissão direta da onda ultrassônica, tendo sido os transdutores do equipamento ultrassônico posicionados ao longo da maior dimensão dos corpos de prova de concreto.

Concretos convencionais e de alta resistência , de ultra-alta resistência (Tsioulou et al., 2017), autoadensáveis (Nik e Omran, 2013; Al-Ridha et al., 2017; Shiade e Tavakoli, 2018) e leves (Al-Ridha et al., 2017) foram os tipos ensaiados pelos autores encontrados na literatura, cujos valores médios de resistência à compressão das vigas situaram-se entre $19 \mathrm{MPa}$ e $112 \mathrm{MPa}$.

Velocidade de Propagação de Onda Ultrassônica em Concretos com Fibras 
Quadro 1 - Características dos corpos de prova de concretos com fibras de outros autores

\begin{tabular}{|c|c|c|c|c|c|}
\hline Autor & $\begin{array}{c}\text { Corpo } \\
\text { de prova }\end{array}$ & $f_{c}(\mathrm{MPa})$ & $\begin{array}{c}\text { Tipo } \\
\text { de fibra }\end{array}$ & $\begin{array}{c}I_{f} \\
(\mathrm{~mm})\end{array}$ & $\begin{array}{c}d_{f} \\
(\mathrm{~mm})\end{array}$ \\
\hline $\begin{array}{c}\text { Gebretsadik } \\
\text { (2013) }\end{array}$ & $\begin{array}{c}\text { Cilindro } \\
100 \mathrm{~mm} \times 200 \mathrm{~mm}\end{array}$ & 60 a 70 & Aço & 19 & 0,60 \\
\hline \multirow{3}{*}{$\begin{array}{c}\text { Nik e Omran } \\
\text { (2013) }\end{array}$} & \multirow{3}{*}{$\begin{array}{l}\text { Cubo } \\
100 \mathrm{~mm}\end{array}$} & \multirow{3}{*}{68 a 89} & Aço & - & - \\
\hline & & & Vidro & - & - \\
\hline & & & Polipropileno & - & - \\
\hline $\begin{array}{l}\text { Rahmani et al. } \\
\qquad \text { (2013) }\end{array}$ & $\begin{array}{l}\text { Cubo } \\
100 \mathrm{~mm}\end{array}$ & 42 a 56 & PET & $\begin{array}{c}0,15 \mathrm{a} \\
7\end{array}$ & - \\
\hline \multirow{2}{*}{$\begin{array}{l}\text { Gaspar } \\
\text { (2016) }\end{array}$} & \multirow{2}{*}{$\begin{array}{c}\text { Cilindro } \\
100 \mathrm{~mm} \times 200 \mathrm{~mm} \\
\mathrm{e} \\
\text { Placa quadrada } \\
300 \mathrm{~mm} \times 150 \mathrm{~mm}\end{array}$} & \multirow{2}{*}{34 a 79} & Aço & 50 & 1,00 \\
\hline & & & Poliolefina & 50 & 0,50 \\
\hline \multirow{2}{*}{$\begin{array}{l}\text { Reufi et al. } \\
\qquad(2016)\end{array}$} & \multirow{2}{*}{-} & \multirow{2}{*}{28 a 39} & Aço & $\begin{array}{c}30 \text { ou } \\
50\end{array}$ & 0,75 \\
\hline & & & Polipropileno & $\begin{array}{l}12,6 \\
\text { ou } 3\end{array}$ & - \\
\hline $\begin{array}{l}\text { Al-Ridha et al. } \\
\text { (2017) }\end{array}$ & $\begin{array}{l}\text { Cubo } \\
100 \mathrm{~mm}\end{array}$ & 19 a 22 & Aço & 50 & 0,50 \\
\hline $\begin{array}{l}\text { Rocha } \\
(2017)\end{array}$ & $\begin{array}{c}\text { Cilindro } \\
100 \mathrm{~mm} \times 200 \mathrm{~mm}\end{array}$ & 40 a 84 & Poliolefina & 35 & 0,50 \\
\hline $\begin{array}{l}\text { Santana } \\
\text { (2017) }\end{array}$ & $\begin{array}{c}\text { Cilindro } \\
100 \mathrm{~mm} \times 200 \mathrm{~mm}\end{array}$ & 35 a 44 & Poliolefina & $\begin{array}{c}35 \text { ou } \\
50\end{array}$ & 0,50 \\
\hline \multirow{2}{*}{$\begin{array}{l}\text { Saraiva } \\
\text { (2017) }\end{array}$} & \multirow{2}{*}{$\begin{array}{c}\text { Cilindro } \\
100 \mathrm{~mm} \times 200 \mathrm{~mm}\end{array}$} & \multirow{2}{*}{50 a 59} & Aço & 50 & 1,00 \\
\hline & & & Poliolefina & 50 & 0,50 \\
\hline $\begin{array}{l}\text { Tsioulou et al. } \\
\text { (2017) }\end{array}$ & $\begin{array}{l}\text { Cubo } \\
100 \mathrm{~mm}\end{array}$ & 102 a 112 & Aço & 13 & 0,16 \\
\hline \multirow{2}{*}{$\begin{array}{l}\text { Hassiba et al. } \\
\qquad(2018)\end{array}$} & \multirow{2}{*}{$\begin{array}{l}\text { Cubo } \\
100 \mathrm{~mm}\end{array}$} & \multirow{2}{*}{70 a 83} & Aço & 50 & 0,50 \\
\hline & & & Polipropileno & 12 & - \\
\hline \multirow{2}{*}{$\begin{array}{l}\text { Shiade e Tavakoli } \\
\text { (2018) }\end{array}$} & \multirow{2}{*}{$\begin{array}{l}\text { Cubo } \\
100 \mathrm{~mm}\end{array}$} & \multirow[b]{2}{*}{64 a 70} & Aço & 36 & 0,70 \\
\hline & & & Polipropileno & $\begin{array}{c}50 \text { ou } \\
60\end{array}$ & $\begin{array}{c}1,6 \text { ou } \\
0,1\end{array}$ \\
\hline \multirow{2}{*}{$\begin{array}{l}\text { Carrillo et al. } \\
\qquad \text { (2019) }\end{array}$} & \multirow{2}{*}{$\begin{array}{c}\text { Cilindro } \\
150 \mathrm{~mm} \times 300 \mathrm{~mm}\end{array}$} & \multirow{2}{*}{37 a 43} & Aço & 50 & 1,05 \\
\hline & & & Polipropileno & 50 & 0,68 \\
\hline \multirow{4}{*}{$\begin{array}{l}\text { Pereira } \\
(2020)\end{array}$} & \multirow{4}{*}{$\begin{array}{c}\text { Cilindro } \\
100 \mathrm{~mm} \times 200 \mathrm{~mm}\end{array}$} & \multirow{4}{*}{24 a 53} & Aço & 25,4 & 1,18 \\
\hline & & & Vidro & 13 & 0,01 \\
\hline & & & Nylon & 19 & 0,04 \\
\hline & & & Polipropileno & 19 & 1,52 \\
\hline
\end{tabular}


A maioria dos estudos encontrados na literatura contemplou o uso de fibras de aço e de fibras de polipropileno, nesta ordem. Gaspar (2016), Rocha (2017), Santana (2017) e Saraiva (2017) utilizaram fibras de poliolefina, enquanto Nik e Omran (2013) e Pereira (2020) fizeram o uso de fibras de vidro. Apenas Rahmani et al. (2013) e Pereira (2020) usaram fibras de PET e de nylon, respectivamente.

\section{Resultados e Análise}

A Figura 4 apresenta os valores médios da resistência à compressão $f_{c}$ em função da velocidade de propagação de onda ultrassônica $V$ dos concretos sem e com fibras, cujos tipos são de aço, polipropileno, poliolefina, vidro, PET e nylon.

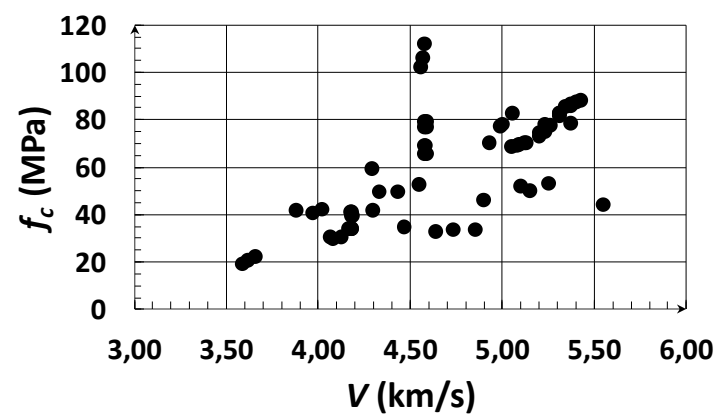

(a) Fibras de aço

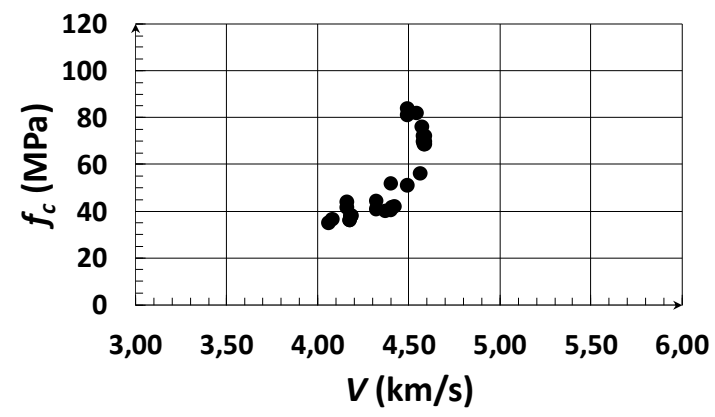

(c) Fibras de poliolefina

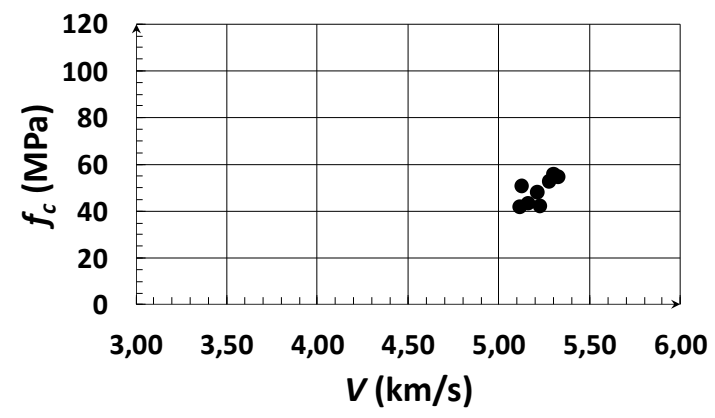

(e) Fibras de PET

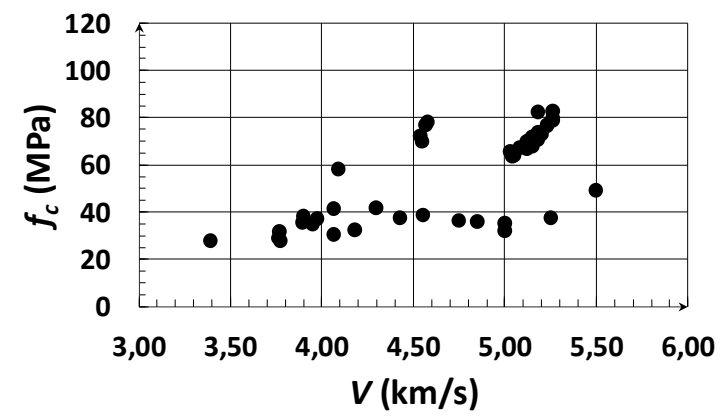

(b) Fibras de polipropileno

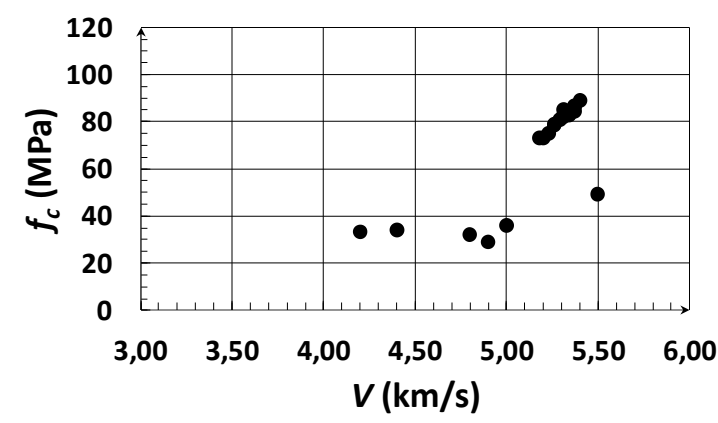

(d) Fibras de vidro

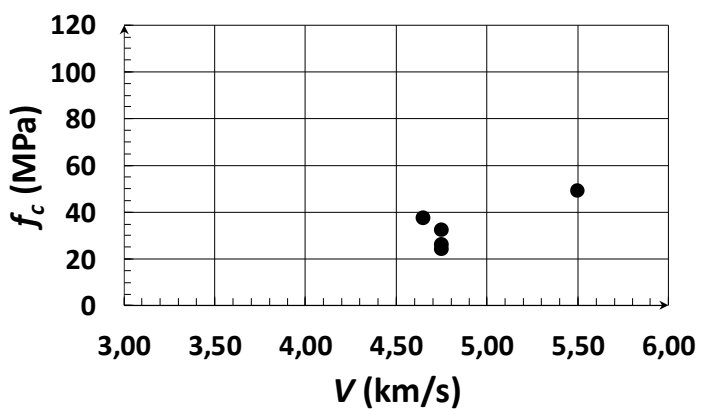

(f) Fibras de nylon

Figura 4 - Valores médios de $f_{c}$ em função de $V$

Verifica-se da Figura 4 que os valores médios de $V$ dos concretos ficaram dentro da faixa de $3,39 \mathrm{~km} / \mathrm{s}$, para o concreto com fibras de polipropileno ( $v$. Figura 4b), a 5,26 km/s, para o concreto com fibras de aço (v. Figura 4a).

Independentemente do tipo de fibras adicionadas ao concreto, nota-se da Figura 4 que os valores médios de $V$ tenderam a aumentar com o incremento dos valores médios de $f_{c}$. Isto é esperado, pois com o incremento dos valores médios de $f_{c}$ o concreto propende a ser mais denso e menos poroso. 
Os valores médios da velocidade de propagação de onda ultrassônica $V$ em função do teor volumétrico das fibras $V_{f}$ dos concretos sem e com fibras estão reunidos na Figura 5.

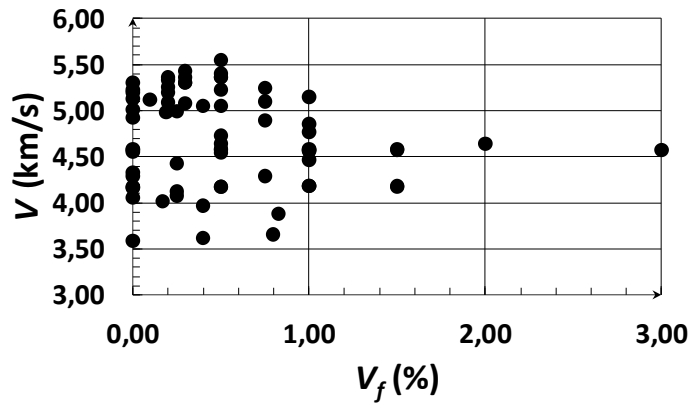

(a) Fibras de aço

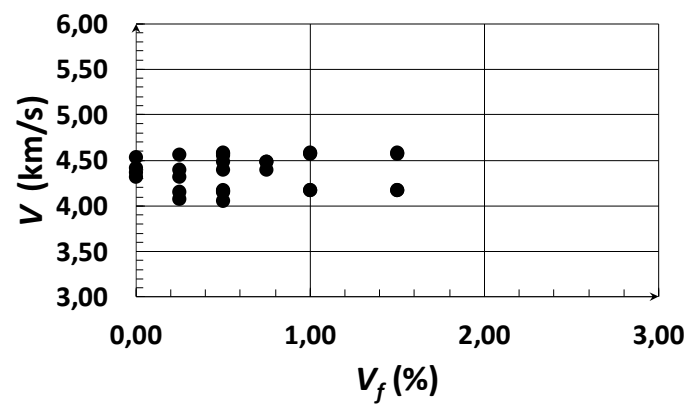

(c) Fibras de poliolefina

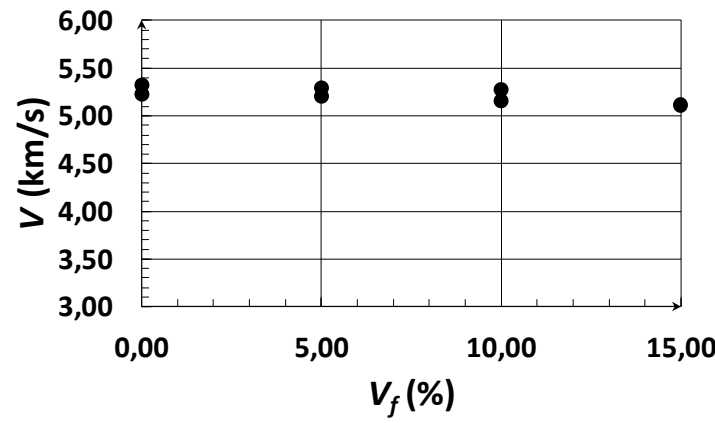

(e) Fibras de PET

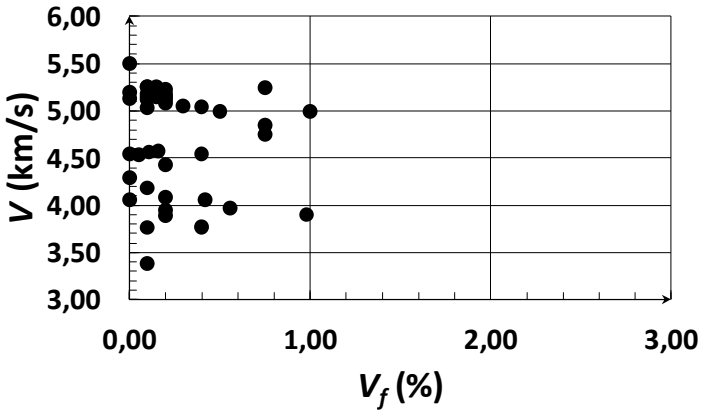

(b) Fibras de polipropileno

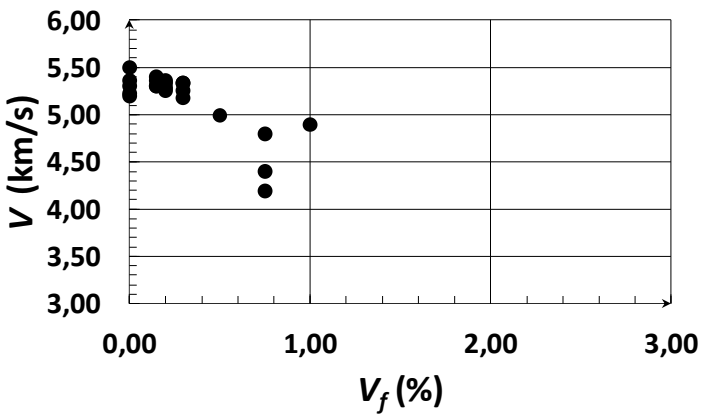

(d) Fibras de vidro

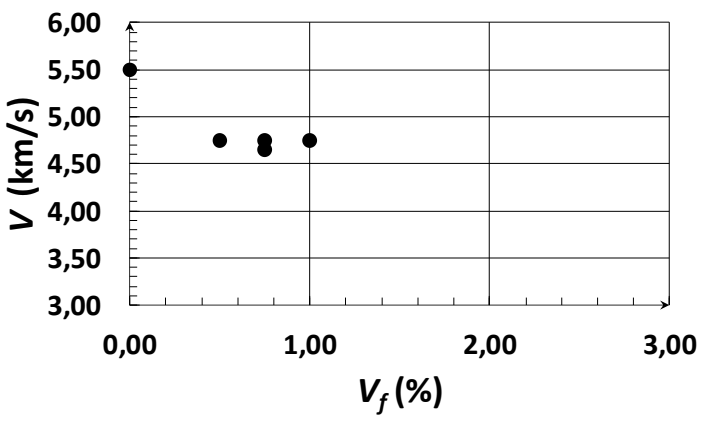

(f) Fibras de nylon

Figura 5 - Valores médios de $V$ em função de $V_{f}$

Em geral, constata-se da Figura 5 que os valores médios de $V$ dos concretos com fibras diminuíram com o acréscimo dos valores de $V_{f}$. A presença de fibras acarreta a formação de poros no concreto, o que leva à diminuição da velocidade de propagação de onda ultrassônica.

Percebe-se da Figura 5 a que os valores médios de $V$ dos concretos sem e com fibras de aço aumentaram com o incremento de $V_{f}$ até o valor de $0,5 \%$, devido à velocidade de propagação de onda ultrassônica do aço ser maior que a do concreto simples, alcançando valores 1,2 vezes a 1,9 vezes maiores (Reufi et al., 2016), e diminuíram para valores de $V_{f}$ acima de $0,5 \%$.

De acordo com as Figuras $5 b$ e $5 c$, os valores médios de $V$ dos concretos com fibras de polipropileno e de poliolefina, que é um tipo de polipropileno de alta resistência, tenderam a se estabilizar com o aumento de $V_{f}$.

Na Figura 6 podem ser vistos os valores médios da resistência à compressão $f_{c}$ em função do teor volumétrico das fibras $V_{f}$ dos concretos sem e com fibras. 
De um modo geral, observa-se nas Figuras $6 \mathrm{~b}, 6 \mathrm{c}, 6 \mathrm{~d}$ e $6 \mathrm{f}$ que os valores médios de $f_{c}$ dos concretos com fibras de polipropileno, de poliolefina, de vidro e de nylon decresceram com o acréscimo de $V_{f}$, com exceção dos concretos com fibras de aço (v. Figura 6a) e PET (v. Figura 6e).

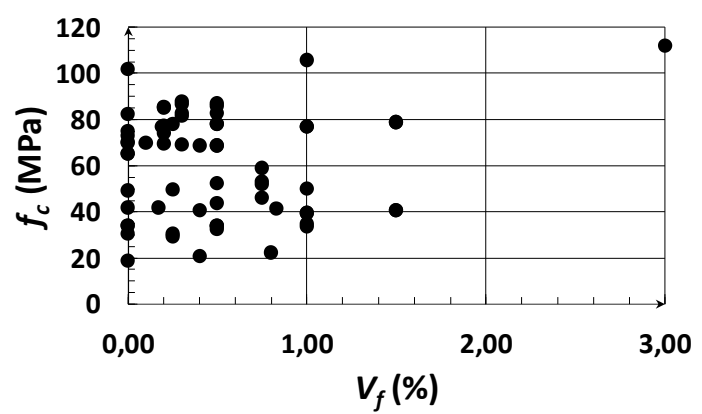

(a) Fibras de aço

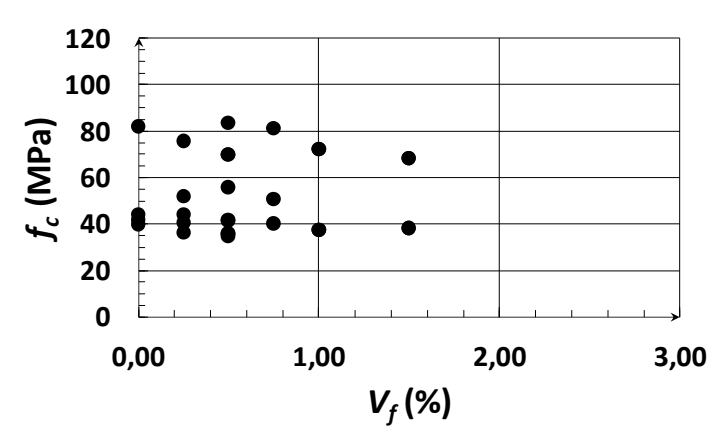

(c) Fibras de poliolefina

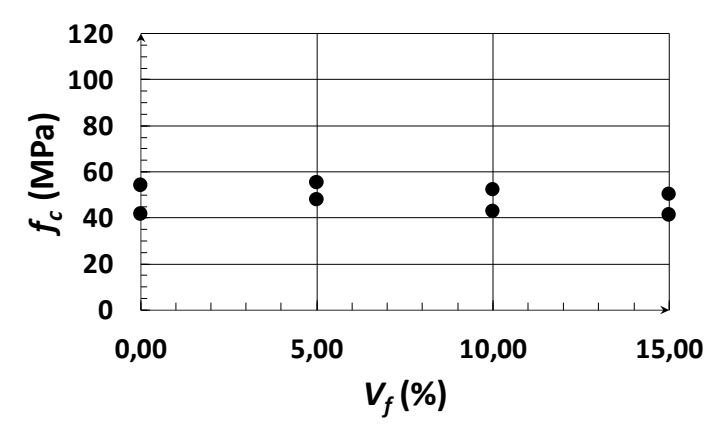

(e) Fibras de PET

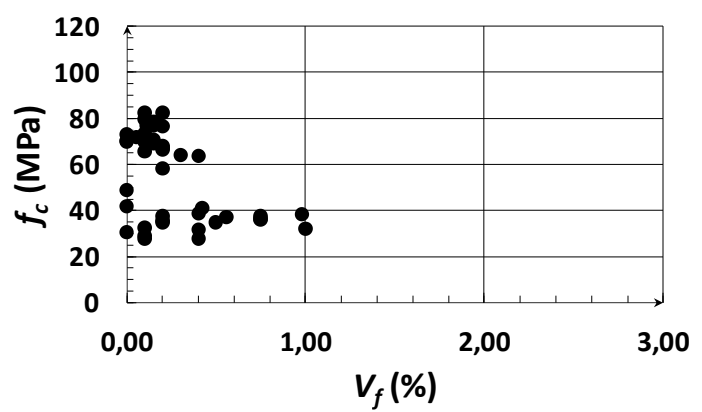

(b) Fibras de polipropileno

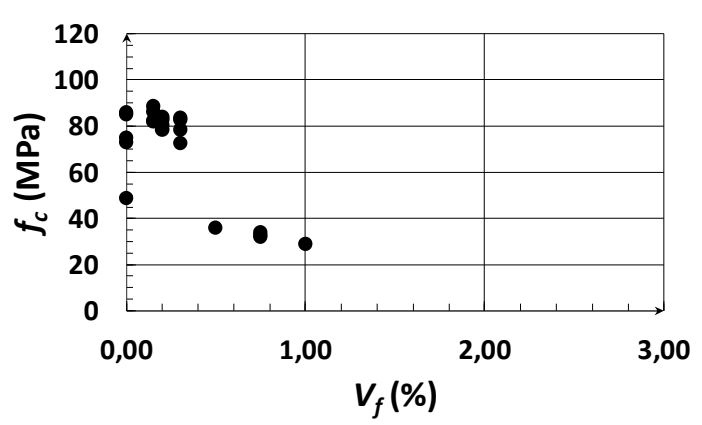

(d) Fibras de vidro

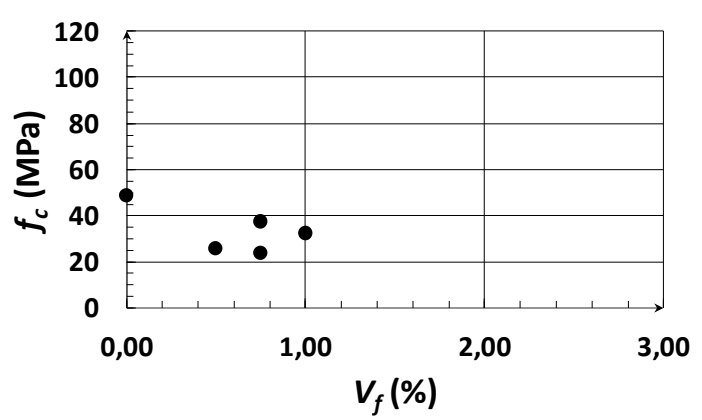

(f) Fibras de nylon

Figura 6 - Valores médios de $f_{c}$ em função de $V_{f}$

Os corpos de prova de concreto com fibras de aço penderam a apresentar maiores valores médios de $f_{c}$ com o crescimento de $V_{f}$ (v. Figura 6a), devido à fibra de aço possuir resistência superior à do concreto simples.

Em contrapartida, os corpos de prova de concreto com fibras de poliolefina tenderam a apresentar menores valores médios de $f_{c}$ com o aumento de $V_{f}(\mathrm{v}$. Figura $6 \mathrm{c}$ ), ainda que a fibra de poliolefina possua resistência superior à do concreto simples.

Os corpos de prova de concreto com fibras de PET (v. Figura 6e) voltaram-se a apresentar valores médios de $f_{c}$ estáveis com o acréscimo de $V_{f}$, apesar da fibra PET possuir resistência inferior à do concreto simples e ter sido adicionada com elevados valores de $V_{f}$.

\section{Conclusões}

Este trabalho apresentou 170 resultados médios de resistência à compressão e de velocidade de propagação de onda ultrassônica de concretos sem ou com diferentes tipos de fibras dispersas e descontínuas (aço, vidro, 
polipropileno, poliolefina, nylon e PET) encontrados na literatura. A partir da análise destes, pôde-se chegar às seguintes conclusões:

- a velocidade de propagação de onda ultrassônica tendeu a aumentar com o incremento da resistência à compressão do concreto, independentemente do tipo de fibras utilizado;

- a velocidade de propagação de onda ultrassônica cresceu com o aumento do teor volumétrico de fibras de aço até o valor de $0,5 \%$, propendeu a se estabilizar com o aumento do teor volumétrico de fibras de polipropileno e de poliolefina, e diminuiu com o aumento do teor volumétrico de fibras de aço a partir de $0,5 \%$;

- a resistência do concreto à compressão pendeu a decrescer com o acréscimo do teor volumétrico de fibras, com exceção dos concretos com fibras de aço, de poliolefina e PET, nos quais os valores médios de $f_{c}$ aumentaram, diminuíram e se estabilizaram, respectivamente;

- parece existir uma relação entre a velocidade de propagação de onda ultrassônica e a resistência à compressão do concreto com fibras.

\section{Referências Bibliográficas}

Al-Ridha, A.S.D., Atshan, A.F., Abbood, A.A., Dheyab, L.S. (2017). Effect of Steel Fiber on Ultrasonic Pulse Velocity and Mechanical Properties of Self-Compact Concrete. International Journal of Innovative Research in Science, Engineering and Technology, 6 (8), 17201-17212.

Associação Brasileira de Normas Técnicas, ABNT NBR 8802 (2019). Concreto Endurecido - Determinação da Velocidade de Propagação de Onda Ultrassônica.

Carrillo, J., Ramirez, J., Lizarazo-Marriagac, J. (2019). Modulus of Elasticity and Poisson's Ratio of FiberReinforced Concrete in Colombia from Ultrasonic Pulse Velocities. Journal of Building Engineering, 23, May, 18-26.

Gaspar, D.H. (2016). Concretos com Fibras Submetidos a Dois Impactos Balísticos. Dissertação de Mestrado. Programa de Pós-graduação em Engenharia de Defesa. Instituto Militar de Engenharia, Brasil.

Gebretsadik, B.T. (2013). Ultrasonic Pulse Velocity Investigation of Steel Fiber Reinforced Self-Compacted Concrete. Thesis of Master of Science. University of Nevada, Las Vegas, United States of America.

Hassiba, B., Mekki, M., Farid, R. (2018). The Relationship Between the Compressive Strength and Ultrasonic Pulse Velocity Concrete with Fibers Exposed to High Temperatures. International Journal of Energetica, 3 (1), 31-36.

Malhotra, V.M., Carino, N.J. (2004). Handbook on Nondestructive Testing of Concrete. CRC Press LLC, Second Edition, United States of America.

Nik, A.S., Omran, O.L. (2013). Estimation of Compressive Strength of Self-compacted Concrete with Fibers Consisting Nano-SiO2 Using Ultrasonic Pulse Velocity. Construction and Building Materials, 44, Jul., 654662.

Pereira, D.A.C. (2020). Prediction of the Compressive Strength and Dynamic Modulus of Fiber Reinforced Concrete by Ultrasonic Pulse Velocity Measurement at Early Ages. Thesis of Master of Science. Georgia Southern University, United States of America.

Rahmani, E., Dehestani, M., Beygi, M.H.A., Allahyari, H., Nikbin, I.M. (2013). On the Mechanical Properties of Concrete Containing Waste PET Particles. Construction and Building Materials, 47, Oct., 1302-1308.

Reufi, E., Marku, J., Bier, T. (2016). Ultrasonic Pulse Velocity Investigation of Polypropylene and Steel Fiber Reinforced Concrete. International Journal of Civil and Environmental Engineering, 10 (3), 332-335.

Rocha, C.A.M. (2017). Concretos com Fibras de Poliolefina para Estruturas de Defesa Submetidos a Elevadas Temperaturas. Dissertação de Mestrado. Programa de Pós-graduação em Engenharia de Defesa. Instituto Militar de Engenharia, Brasil.

Santana, C.S.A. (2017). Propriedades de Concretos Projetados com Fibras de Poliolefina para Túneis. Dissertação de Mestrado. Programa de Pós-graduação em Engenharia de Transportes. Instituto Militar de Engenharia, Brasil.

Velocidade de Propagação de Onda Ultrassônica em Concretos com Fibras 
Saraiva, R.M.D.C. (2017). Resistência à Fadiga na Flexão de Concretos com Fibras de Aço e de Poliolefina para Estruturas de Defesa. Tese de Doutorado. Programa de Pós-graduação em Engenharia de Defesa. Instituto Militar de Engenharia, Brasil.

Shiade, M.F., Tavakoli, H.R. (2018). Estimation of Mechanical and Durability Properties of Self Compacting Concrete with Fibers Using Ultrasonic Pulse Velocity. Journal of Rehabilitation in Civil Engineering, 6 (2), 43-53

Tsioulou, O., Lampropoulos, A., Paschalis, S. (2017). Combined Non-Destructive Testing (NDT) Method for the Evaluation of the Mechanical Characteristics of Ultra High Performance Fibre Reinforced Concrete (UHPFRC). Construction and Building Materials, 131, 66-77. 